\title{
Understanding wine sorption by oak wood: Modeling of wine uptake and characterization of volatile compounds retention
}

\author{
Eduardo Coelho*, Lucília Domingues, José António Teixeira, José Maria Oliveira, Teresa Tavares \\ CEB - Centre of Biological Engineering, University of Minho, Campus Gualtar, 4710-057 Braga, Portugal
}

\section{A R T I C L E I N F O}

\section{Keywords:}

Wine ageing

Wood sorption

Volatile compounds

Oak wood

Mathematical models

Aroma recombination

\begin{abstract}
A B S T R A C T
Cooperage wood is a porous material and beverages exchange compounds with it by penetrating into its pores. This work demonstrates the enrichment of wood with wine during ageing. Three oak varieties were cut into different sized chips and immersed in fortified wine and water. Wine and water uptake were measured along time and sorption was described based on a saturation empirical model. Maximum uptake varied among wood types and was independent of particle size, which affected only equilibrium time. Sorption of wine volatiles such as alcohols, esters and acids in wood was shown, which was also dependent on wood type and independent of particle size. Multivariate analysis demonstrated differences and similarities in depletion of wood extractives and sorption of wine volatiles depending on wood variety. Sorption shown in this work demonstrates wood as a vector for aroma recombination, when reused for ageing between different beverages.
\end{abstract}

\section{Introduction}

Ageing is a key factor in the production of alcoholic beverages and spirits, essential for the final quality of the product. Traditionally, ageing is performed by storing the beverage in wood barrels. Oak is the preferred cooperage wood, where the extraction of its compounds (additive ageing) and reaction and evaporation of beverage compounds (subtractive ageing) enhance the sensory character of the final product (Mosedale \& Puech, 1998). Accelerated ageing processes are also used, which resort to soaking wood in the beverage in vats, mimicking and accelerating phenomena occurring in the barrel (Canas, Caldeira, \& Belchior, 2013; del Álamo, Nevares, Gallego, Martin, \& Merino, 2008). Traditionally, oak wood can be reused and goes from the ageing of one beverage to another. For instance, scotch whisky production resorts to woods previously used in other beverages ageing such as Bourbon or Sherry, being also reported the reuse of Port or Madeira wine casks for the finishing steps (Mosedale, 1995; Russell, 2003). Beer ageing also resorts to the reuse of woods from other beverages, as the example of Lambic beers which reuse casks previously used in wine ageing (Spitaels et al., 2014).

During ageing, several wood compounds are extracted by the hydroalcoholic matrix with well documented impact on the beverage properties (De Rosso, Cancian, Panighel, Dalla Vedova, \& Flamini, 2009; Garde-Cerdán \& Ancín-Azpilicueta, 2006; Le Floch, Jourdes, \& Teissedre, 2015). Wood can be reused a finite number of times during which it becomes depleted of extractives (Mosedale \& Puech, 1998; Wilkinson, Li, Grbin, \& Warren, 2013). Besides becoming depleted of extractives, several other additive transformations occur to wood during ageing. For instance, wine has a complex endogenous microflora which during contact adheres and grows on the wood surface in the form of biofilms (Bastard et al., 2016). This has been shown to impart the ageing of other beverages when reusing the cask (Spitaels et al., 2014). Also, tartaric acid present in wine precipitates mainly in the form of potassium hydrogen tartrate crystals at wood surface (OrtegaHeras, González-Sanjosé, \& González-Huerta, 2007). With more interest to the present work, wood sorption of beverage compounds, namely volatile compounds which influence sensory properties, also occurs. Ramirez and collaborators demonstrated that terpene alcohols, esters, aldehydes and norisoprenoids concentrations in wine decreased in the presence of wood, especially for linalool and ethyl octanoate. Such decrease was described as selective and did not depend on solubility of the compounds but instead on acid, base and polar characteristics (Ramirez et al., 2001). Barrera-García and collaborators demonstrated the sorption of monomeric volatile phenols in the wood-wine interface (Barrera-García, Gougeon, Voilley, \& Chassagne, 2006) and also the sorption of polyphenols in wood, with the disappearance of monomeric anthocyanins, (+)-catechin, (-)-epicatechin, and trans-resveratrol in the presence of wood (Barrera-García et al., 2007). Later, BarreraGarcía and collaborators also demonstrated that cellulose, hemicellulose and lignin were involved in sorption selectivity of phenolic

\footnotetext{
* Corresponding author.

E-mail address: e.coelho@ceb.uminho.pt (E. Coelho).
} 
compounds by wood (Barrera-García, Gougeon, Karbowiak, Voilley, \& Chassagne, 2008). To our knowledge, these works cover most of the scientific research on wood sorption of chemical compounds during ageing of alcoholic beverages, and focus mainly on the subtractive changes that occur to the beverage.

Therefore, considering that wood reuse is common, detailed knowledge of beverage sorption is of upmost importance to understand its impact during the subsequent reutilizations. If we consider that wood becomes enriched with the beverage, it can be a vector for transferring sensory properties from one product to another.

This work focuses on transformations occurring to wood by sorption of wine, taking into account mass transfer and retention of wine volatiles in wood. For the first time, sorption was studied using a real fortified wine in three different types of wood, covering mass transfer into wood with the establishment of empirical mathematical models for wine uptake. Retention of volatiles was not only demonstrated but was also shown to differ among the studied woods.

\section{Materials and methods}

\subsection{Chemicals and materials}

The following chemicals were used as standards for the GC-MS analysis: 3-methyl-1-butanol ( $\geq 99.8 \%$ ), 2-methyl-1-propanol ( $\geq$ 99.9\%), 1-hexanol ( $\geq 99.9 \%), Z$-3-hexenol ( $\geq 90 \%$ ), 2-phenylethanol ( $\geq 99 \%$ ), hexanoic acid ( $\geq 98 \%$ ), furfural (99\%), vanillin ( $\geq 98 \%$ ), from Fluka; benzyl alcohol ( $\geq 99 \%$ ), etyl butyrate ( $\geq 99 \%$ ), isoamyl acetate ( $\geq 99 \%$ ), ethyl hexanoate ( $\geq 99 \%$ ), ethyl lactate (98\%), ethyl octanoate ( $\geq 99 \%$ ), ethyl-3-hydroxybutyrate (99\%), diethyl succinate (99\%), diethyl malate $(\geq 97 \%)$, ethyl hexadecanoate $(\geq 99 \%)$, monoethyl succinate (90\%), octanoic acid ( $\geq 99.5 \%$ ), 5-methylfurfural (99\%), 4-methylguaiacol ( $\geq 98 \%)$, 4-propylguaiacol ( $\geq 99 \%$ ), guaiacol (98\%), 2,6-dimethoxyphenol (99\%), eugenol (99\%), cis/transoak lactone ( $\geq 98 \%$ ), 4-ethylbenzaldehyde (98\%), acetovanillone (98\%), syringaldehyde (98\%) from Aldrich; 5-hydroxymethylfurfural (98\%) from Acros Organics and 4-ethylguaiacol (98\%) from Alfa Aesar. The remaining compounds were identified on the basis of the NIST spectrum collection.

Fortified wine used for the sorption assays was kindly provided by Quinta do Portal S.A., and is used for Port wine production in the Douro demarcated region. Wine had an ethanol content, by volume, of $20.9 \% \pm 0.3 \%$, and a volumetric mass density of $0.9861 \mathrm{~g} \mathrm{~cm}^{-3} \pm 0.0007 \mathrm{~g} \mathrm{~cm}^{-3}$. Toasted French oak ( $\mathrm{M}+$ toast) $950 \times 50 \times 18 \mathrm{~mm}^{3}$, toasted American oak (M+ toast) $950 \times 50 \times 6 \mathrm{~mm}^{3}$ and untoasted American oak $950 \times 50 \times 6 \mathrm{~mm}^{3}$ staves, from the Oenostave $^{\circledR}$ series (kindly provided by Seguin Moreau), were used in this work. Toasted staves were used with the $\mathrm{M}+$ toasting level, which in cooperage generally corresponds to a $68 \mathrm{~min}$ toast at $62{ }^{\circ} \mathrm{C} \pm 3{ }^{\circ} \mathrm{C}$ without water addition (Chira \& Teissedre, 2014).

\subsection{Structural analysis of oak woods}

Structural properties of woods were characterized at Instituto Pedro Nunes (Coimbra, Portugal), using whole wood pieces without grinding. Mercury porosimetry, which analyses pores between $5.5 \mathrm{~nm}$ and $360 \mu \mathrm{m}$, was performed using a Micromeritics AutoPore IV 9500 following the ISO 15901-1:2016 procedures. BET porosimetry, which analyses pores between $1 \mathrm{~nm}$ and $0.3 \mu \mathrm{m}$, was measured using a Micromeritics ASAP 2000 surface area analyzer following the procedures of ISO 9277:2010. A desktop Scanning Electron Microscope (SEM) (Phenom ProX, Netherlands) was used for microscopy. Samples were added to aluminum pin stubs with electrically conductive carbon adhesive tape (PELCO Tabs ${ }^{\mathrm{TM}}$ ), which were placed inside a Phenom Standard Sample Holder. The analysis was conducted at $5 \mathrm{kV}$ with intensity image. All results were acquired using the ProSuite software.

\subsection{Sorption conditions}

The three different oak woods used for the uptake and sorption studies were cut into $3 \mathrm{~mm} \times 3 \mathrm{~mm} \times 6 \mathrm{~mm}$ (small- $\mathrm{S}$ ), $7 \mathrm{~mm} \times 7 \mathrm{~mm} \times 6 \mathrm{~mm}$ (medium- M) and $10 \mathrm{~mm} \times 10 \mathrm{~mm} \times 6 \mathrm{~mm}$ (large- L) chips. Wood staves were cut with a vertical saw in the transversal direction and then individually cut using a blade in the longitudinal direction of wood. All chips were verified for their dimensions with a pachymeter. Woods were put in contact with fortified wine, and distilled water as control, at a concentration of $50 \mathrm{~g} \mathrm{~L}^{-1}$ in Pyrex tubes fitted with Teflon caps. Isotherm conditions were maintained at $20^{\circ} \mathrm{C}$ with $150 \mathrm{~min}^{-1}$ orbital agitation. Uptake was accompanied by determination of mass variation in wood throughout contact time, until equilibrium was attained. For such, wood chips were recovered periodically, excess wine at wood surface was eliminated with an absorbent and wood chips were weighed in a Mettler AE 200 analytical scale. Uptake was calculated as percentage of mass variation referred to the initial mass, taking also into account the initial moisture of wood, determined with a Radwag MAC/50/1/NH moisture analyzer. All woods remained in contact with wine until equilibrium was observed for all the tested conditions. The state of equilibrium was assumed when no mass variation was observed for three consecutive measurements. Wood-wine contact was performed in independent triplicates for each condition.

\subsection{Modeling of uptake}

Modeling of uptake by wood was performed by non-linear regression. For that a regression was performed to verify the adjustment of the model proposed in the following equation to the experimental data:

$U(t)=\frac{t \times U_{\max }}{K_{U}+t}+H_{\mathrm{i}}$

where $U(t)$ is the uptake expressed as percentage of mass gained, $t$ is time, $U_{\max }$ is the maximum uptake expressed as percentage of mass gained, $K_{U}$ is the time needed for reaching half of $U_{\max }$ and $H_{\mathrm{i}}$ is the initial moisture in mass percentage. For the regression, the sum of squared errors between the predicted and experimental data was minimized using the Excel solver, by the modification of $U_{\max }$ and $K_{U}$ values. Errors associated to the regression coefficients were calculated for a $95 \%$ confidence interval.

\subsection{Extraction of volatiles from wood}

In order to determine the presence of volatile compounds in woods, an extraction step was performed on the basis of previous works (Caldeira, Clímaco, Bruno de Sousa, \& Belchior, 2006). Woods were ground to particles of diameter $<1 \mathrm{~mm}$, and mixed at a concentration of $50 \mathrm{~g} \mathrm{~L}^{-1}$, using a $55 \%$ hydroalcoholic solution, $\mathrm{pH} 4.6$. Contact between wood and the hydroalcoholic solution was performed in $10 \mathrm{~mL}$ Pyrex tubes with Teflon caps, at $20^{\circ} \mathrm{C}$ with rotary agitation during $24 \mathrm{~h}$ to ensure total extraction of wood content. Afterwards, the hydroalcoholic solution was separated from woods by centrifugation at $2700 \mathrm{~g}$ during 10 min followed by decantation of the clear extracts.

\subsection{Analysis of volatile compounds}

Volatiles in the hydroalcoholic extracts were analyzed by gas chromatography coupled with mass spectrometry (GC-MS). Extraction was performed in $8 \mathrm{~mL}$ of diluted wood extract samples, by a factor of 4 , with $400 \mu \mathrm{L}$ of dichloromethane (SupraSolv for gas chromatography, Merck), after adding 4-nonanol as internal standard (2.4 $\mu \mathrm{g})$. Extracts were analyzed in a gas chromatograph Varian 3800 equipped with a 1079 injector and an ion-trap mass spectrometer Varian Saturn 2000. Each $1 \mu \mathrm{L}$ injection was made in splitless mode (30 s) in a Sapiens-Wax MS column ( $30 \mathrm{~m} \times 0.15 \mathrm{~mm}$; $0.15 \mu \mathrm{m}$ film thickness, Teknokroma). 
Table 1

Structural characterization of French and American oak woods by mercury and BET porosimetry

\begin{tabular}{lll}
\hline & Toasted French oak & Toasted American Oak \\
\hline $\begin{array}{l}\text { Mercury porosimetry } \\
\text { Intrusion Specific } \\
\quad \text { Volume }\left(\mathrm{cm}^{3} \mathrm{~g}^{-1}\right)\end{array}$ & $74.8 \times 10^{-2} \pm 2.1 \times 10^{-2}$ & $75.2 \times 10^{-2} \pm 2.1 \times 10^{-2}$ \\
$\begin{array}{c}\text { Total Pore Specific Area } \\
\left(\mathrm{m}^{2} \mathrm{~g}^{-1}\right)\end{array}$ & $49.3 \pm 1.4$ & $41.3 \pm 1.1$ \\
$\begin{array}{c}\text { Average Pore radius } \\
(\mathrm{nm})\end{array}$ & $30.4 \pm 0.1$ & $36.4 \pm 0.1$ \\
$\begin{array}{c}\text { Porosity (\%) } \\
\text { BET porosimetry } \\
\text { Specific Surface area } \\
\left(\mathrm{m}^{2} \mathrm{~g}^{-1}\right)\end{array}$ & $50.9 \pm 1.4$ & $51.9 \pm 1.4$ \\
$\begin{array}{c}\text { Total Pore Specific } \\
\quad \text { Volume }\left(\mathrm{cm}^{3} \mathrm{~g}^{-1}\right)\end{array}$ & $4.6 \times 10^{-4} \pm 0.2 \times 10^{-4}$ & $5.1 \times 10^{-4} \pm 0.2 \times 10^{-4}$ \\
$\begin{array}{c}\text { Average Pore diameter } \\
(\mathrm{nm})\end{array}$ & $6.8 \pm 0.1$ & $6.2 \pm 0.1$ \\
\hline
\end{tabular}

Carrier gas was helium 49 (Praxair) at a constant flow of $1.3 \mathrm{~mL} \mathrm{~min}^{-1}$. The detector was set to electronic impact mode with an ionization energy of $70 \mathrm{eV}$, a mass acquisition range from $\mathrm{m} / \mathrm{z} 35$ to $\mathrm{m} / \mathrm{z} 260$ and $610 \mathrm{~ms}$ acquisition interval. The oven temperature was initially set to $60{ }^{\circ} \mathrm{C}$ for $2 \mathrm{~min}$ and then raised to $234^{\circ} \mathrm{C}$ at a rate of $3^{\circ} \mathrm{C} \mathrm{min}{ }^{-1}$, raised again to $260{ }^{\circ} \mathrm{C}$ at $5{ }^{\circ} \mathrm{C} \mathrm{min}^{-1}$ and finally maintained at $260^{\circ} \mathrm{C}$ for $10 \mathrm{~min}$. Injector temperature was set to $250^{\circ} \mathrm{C}$ with a $30 \mathrm{~mL} \mathrm{~min}^{-1}$ split flow and transfer line was maintained at $250^{\circ} \mathrm{C}$. Compounds were identified using MS Workstation version 6.9 (Varian) software, by comparing mass spectra and retention indices with those of pure standards and quantified as 4-nonanol equivalents. PCA analysis was performed using Statsoft Statistica 7 software.

\section{Results and discussion}

\subsection{Structural analysis of oak wood}

In order to investigate oak wood capacity as a sorbent, its porosity was assessed by mercury porosimetry and BET porosimetry. The results are presented in Table 1 .

Wood is acknowledged as a porous material due to its structure, where hollow lumens exist within the individual fibers, interlinked with lignin (Mackay \& Gschwend, 2000; Zillig, Janssen, Carmeliet, \& Derome, 2006). This can be observed in Fig. 1, where the pores are clearly visible on the surface of cut French wood. Porosities were of 50.9\% for French and 51.9\% for American oak, with similar intrusion volumes of $74.8 \times 10^{-2} \mathrm{~cm}^{3} \mathrm{~g}^{-1}$ and $75.2 \times 10^{-2} \mathrm{~cm}^{3} \mathrm{~g}^{-1}$, respectively. Such values are coherent with the ones previously reported for oak woods (Ding, Koubaa, Chaala, Belem, \& Krause, 2008; Plötze \& Niemz, 2011). As a consequence of its porosity, oak wood demonstrated a large internal surface area associated to pores, of $49.3 \mathrm{~m}^{2} \mathrm{~g}^{-1}$ for French oak and $41.3 \mathrm{~m}^{2} \mathrm{~g}^{-1}$ for American oak.

The difference in surface area among the analyzed oak types can be directly correlated with the differences observed in average pore diameters. French oak presented a lower average pore diameter than American oak, which were of $30.4 \mathrm{~nm}$ and $36.4 \mathrm{~nm}$, respectively. Porosity in oak wood was characterized mainly in the form of mesopores, within the $2 \mathrm{~nm}$ and $50 \mathrm{~nm}$ interval (Leofanti, Padovan, Tozzola, \& Venturelli, 1998). When comparing the results of mercury porosimetry with those of BET porosimetry, most of surface area was associated with pores averaging a $30 \mathrm{~nm}$ diameter, whereas smaller pores had low expression in the overall void volume. For instance in French oak, the volume associated with pores averaging $6.8 \mathrm{~nm}$ radius was only of $4.6 \times 10^{-4} \mathrm{~cm}^{3} \mathrm{~g}^{-1}$, largely inferior to the one previously discussed for mercury porosimetry. The same behavior was observed for American oak where the volume associated with pores was slightly

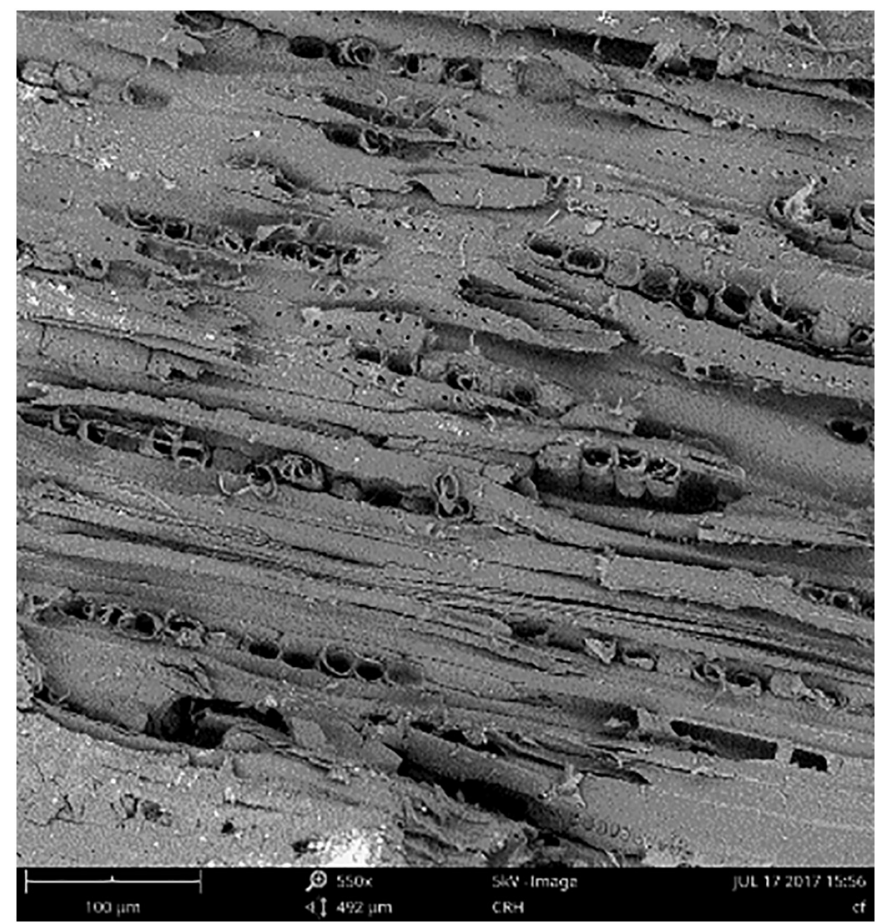

Fig. 1. Scanning Electron Microscopy (SEM) image of toasted French oak chip surface.

higher than the French variety but still only accounted for $5.1 \times 10^{-4}$ $\mathrm{cm}^{3} \mathrm{~g}^{-1}$ for an average pore diameter of about $6.2 \mathrm{~nm}$. Contrary to the observed for micropores, average diameter of pores in American oak was lower than the observed for French oak, which justifies the higher BET surface area observed for American oak.

\subsection{Modeling of wine uptake by wood}

Taking into account the porous nature of wood and on the basis of a submerged wood-wine contact system, chips of different sizes of toasted French, toasted American and untoasted American oak were put in contact with wine and water, which served as control. Uptake of liquid was monitored on a mass percentage basis, with the sorption kinetics presented in Fig. 2. It can bee seen that both wine and water uptake showed saturation profiles, with most of the uptake occurring in the first two days for French oak and in the first five days for American and untoasted American oak. Uptake profiles are coherent with the previously described for water sorption in isotherm conditions (Engelund, Thygesen, Svensson, \& Hill, 2013). For the overall particle sizes, French oak stabilized earlier than American oak, needing only 14 days for full stabilization whereas American oak stabilized later, at around 35 days to 40 days for toasted and 30 days to 35 days for the untoasted variety. For a better understanding of the differences in uptake kinetics, nonlinear regressions were performed, which allowed the comparison between the different conditions studied regarding two main variables: maximum uptake of wood $\left(U_{\max }\right)$ and time needed to attain half of the observed maximum uptake $\left(K_{U}\right)$. Initial moisture $\left(H_{\mathrm{i}}\right)$ in wood was also taken into account considering that it would influence maximum uptake capacity. $U_{\max }$ and $K_{U}$ obtained for each condition are listed in Table 2. A good correlation was found between wood uptake kinetics and the proposed empirical model, as visible by the $R^{2}$ obtained from the non-linear regressions. In the majority of conditions tested, regression coefficients were higher than 0.99 , only with the exception of uptake of wine by toasted American oak which presented lower $R^{2}$ values but still higher than 0.95 . Therefore, the proposed empirical model properly represents the sorption kinetics under study.

Maximum uptake observed $\left(U_{\max }\right)$, ranged between $38 \%$ and $43 \%$ 
a)
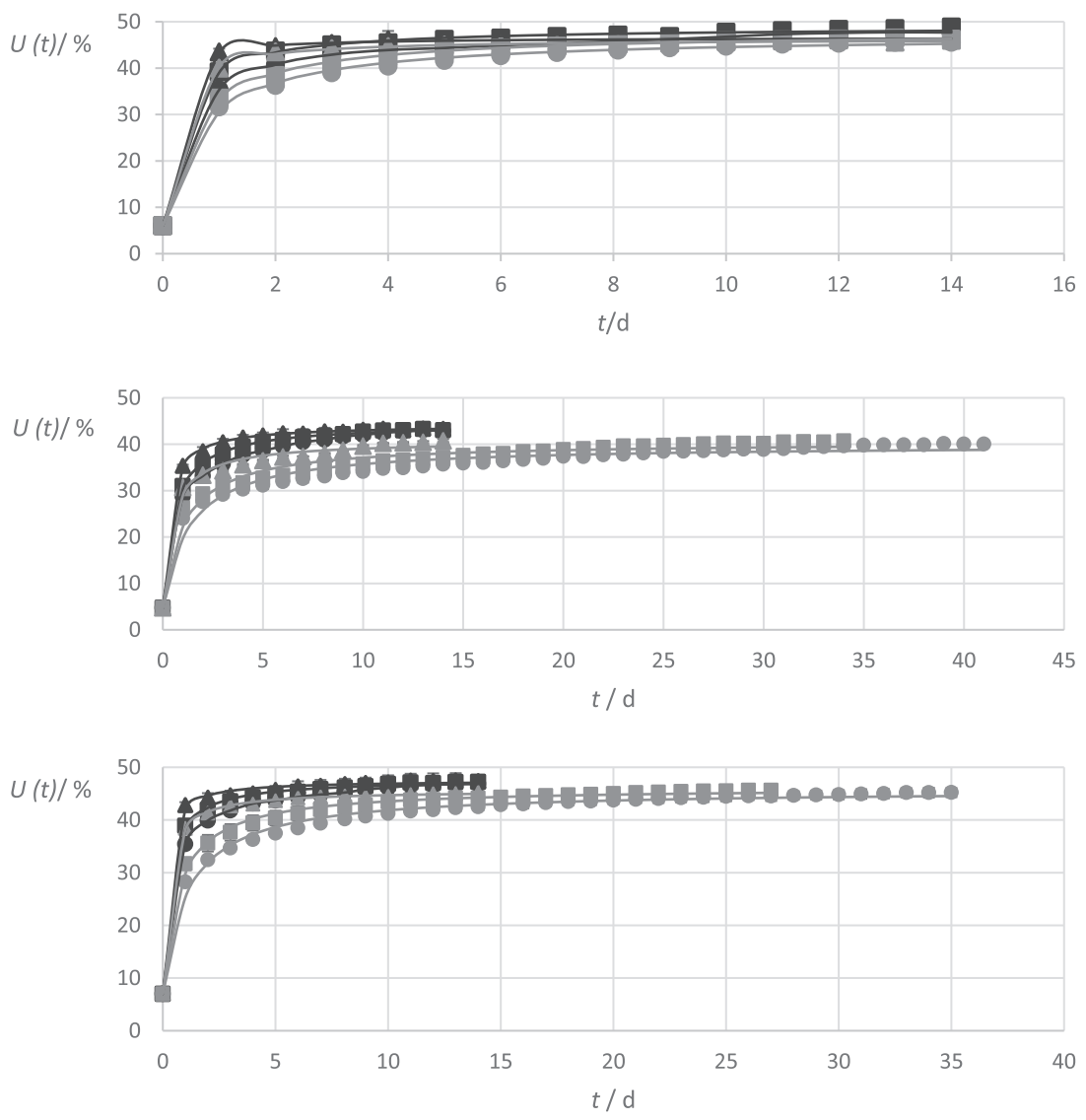

Fig. 2. Uptake $[U(t)]$ throughout time $(t)$ of small (triangles), medium (squares) and large (circles) chips for a) toasted French oak, b) toasted American oak and c) untoasted American oak in contact with fortified wine (grey) and water (black), along with the corresponding kinetic models obtained by non-linear regression (lines).

Table 2

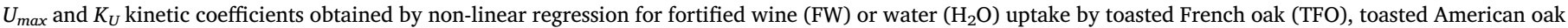

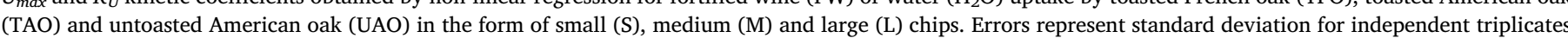

\begin{tabular}{|c|c|c|c|c|c|c|c|c|c|c|}
\hline \multirow[b]{2}{*}{ Wood } & \multirow[b]{2}{*}{ Matrix } & \multicolumn{3}{|l|}{$K_{U} / \mathrm{d}$} & \multicolumn{3}{|l|}{$U_{\max } / \%$} & \multicolumn{3}{|l|}{$R^{2}$} \\
\hline & & $\mathrm{S}$ & M & $\mathrm{L}$ & $S$ & M & $\mathrm{L}$ & $\mathrm{S}$ & M & $\mathrm{L}$ \\
\hline TFO & $\mathrm{H}_{2} \mathrm{O}$ & $0.09 \pm 0.03$ & $0.30 \pm 0.04$ & $0.47 \pm 0.05$ & $40.54 \pm 0.31$ & $42.87 \pm 0.42$ & $42.51 \pm 0.46$ & 0.9988 & 0.9983 & 0.9982 \\
\hline$\left(H_{\mathrm{i}}=6 \%\right)$ & FW & $0.18 \pm 0.02$ & $0.56 \pm 0.03$ & $0.68 \pm 0.07$ & $40.27 \pm 0.20$ & $41.84 \pm 0.28$ & $41.08 \pm 0.58$ & 0.9995 & 0.9994 & 0.9977 \\
\hline TAO & $\mathrm{H}_{2} \mathrm{O}$ & $0.30 \pm 0.02$ & $0.56 \pm 0.04$ & $0.76 \pm 0.10$ & $39.40 \pm 0.20$ & $39.82 \pm 0.36$ & $39.86 \pm 0.71$ & 0.9996 & 0.9989 & 0.9961 \\
\hline$\left(H_{\mathrm{i}}=4 \%\right)$ & FW & $0.49 \pm 0.14$ & $1.06 \pm 0.20$ & $1.36 \pm 0.23$ & $35.99 \pm 1.09$ & $35.77 \pm 0.72$ & $35.17 \pm 0.66$ & 0.9866 & 0.9633 & 0.9590 \\
\hline UAO & $\mathrm{H}_{2} \mathrm{O}$ & $0.16 \pm 0.04$ & $0.31 \pm 0.04$ & $0.47 \pm 0.05$ & $40.50 \pm 0.45$ & $40.72 \pm 0.40$ & $40.76 \pm 0.44$ & 0.9976 & 0.9983 & 0.9983 \\
\hline$\left(H_{\mathrm{i}}=7 \%\right)$ & FW & $0.24 \pm 0.02$ & $0.72 \pm 0.07$ & $1.12 \pm 0.12$ & $38.59 \pm 0.18$ & $39.16 \pm 0.36$ & $38.73 \pm 0.43$ & 0.9996 & 0.9938 & 0.9864 \\
\hline
\end{tabular}

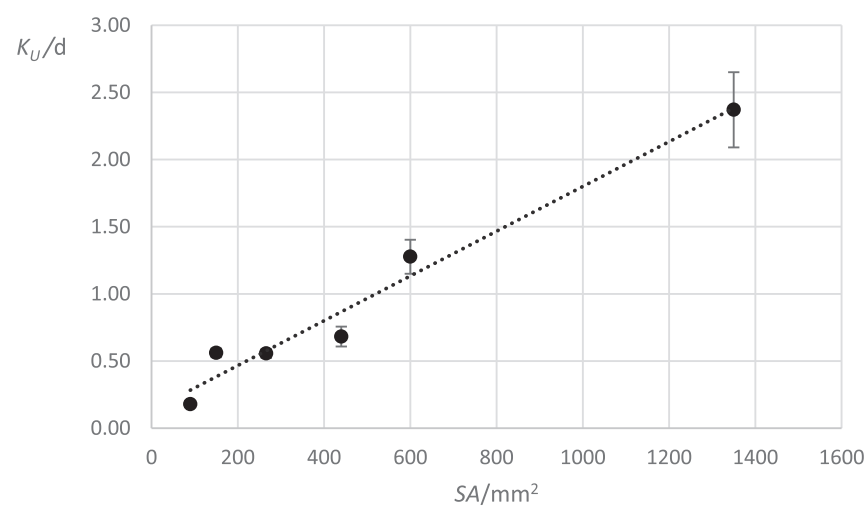

Fig. 3. Correlation between particle surface area $(S A)$ and the time needed to attain half of the maximum uptake $\left(K_{U}\right)$ for toasted French Oak in contact with Fortified Wine $\frac{K_{U}}{\mathrm{~d}}=0.0017 \times \frac{S A}{\mathrm{~mm}^{2}}+0.1332$. for all the conditions tested. French oak showed slight differences in water and wine uptake but these were not statistically significant for a 95\% confidence interval. However, statistically significant differences in water and wine uptake were found between toasted and untoasted American oak. For all particle sizes, maximum uptake of water was lower than maximum uptake of wine, with the highest difference observed in toasted American oak, when compared with the untoasted variety. Such differences in uptake can be explained by the different densities of each matrix. Fortified wine used in this work presented a density of $0.9861 \mathrm{~g} \mathrm{~cm}^{-3}$ and therefore lower than water, which can be attributed to its high ethanol content (21\%, by volume) (RibéreauGayon, Glories, Maujean, \& Dubourdieu, 2006). Therefore differences in $U_{\text {max }}$ can be expected considering that it was determined on a mass basis. Regarding comparisons between oak varieties, no statistically significant differences were found in water uptake for toasted and untoasted American oak in the different chip sizes tested. However, wine uptake was significantly higher for untoasted American oak when compared with the toasted variety. For French oak, water uptake was 


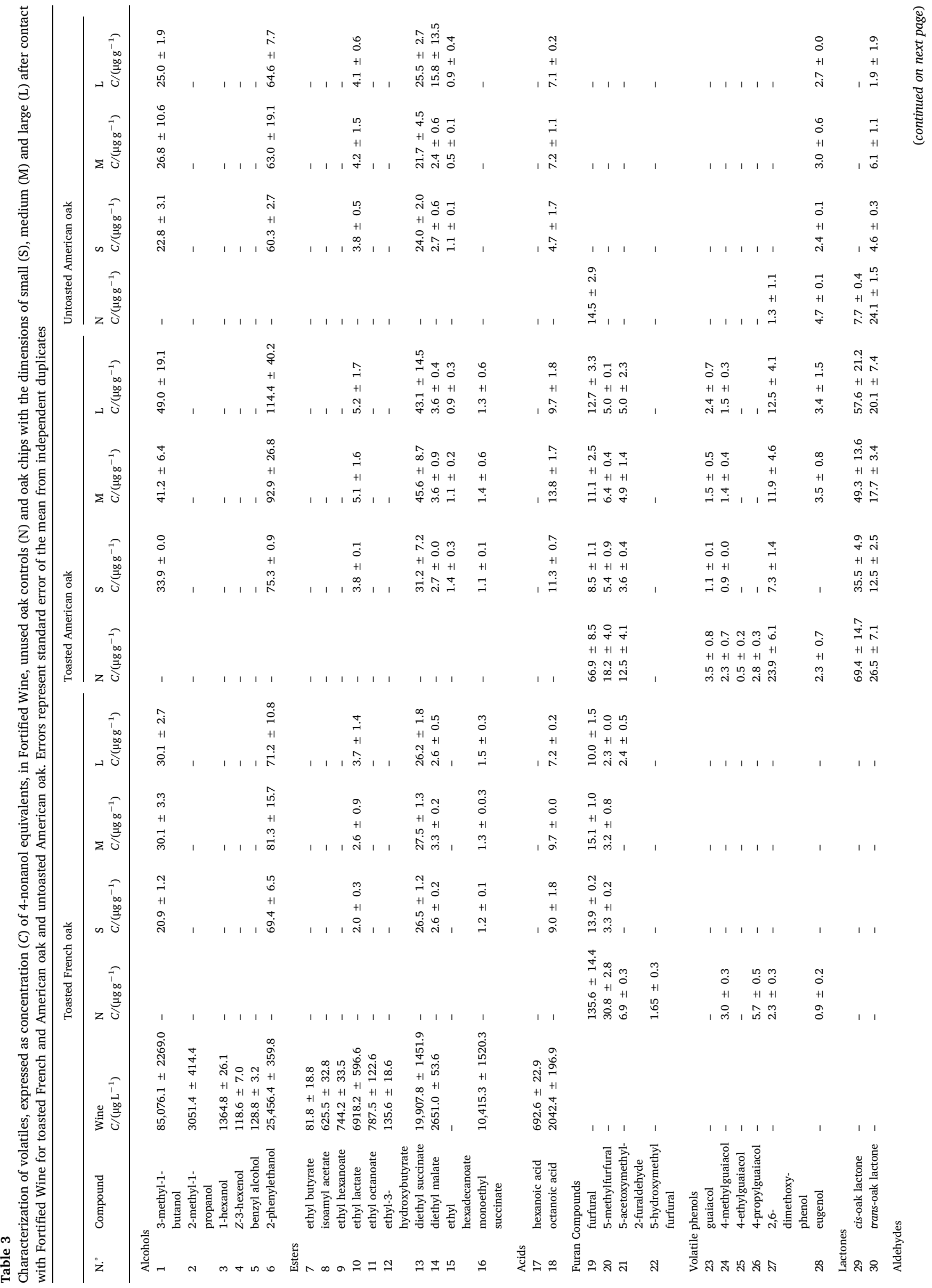


higher when compared with American oak, either toasted or untoasted, with only the small chips being significantly different. Wine uptake was also higher in French oak when compared with both American varieties for all the particle sizes. Considering the similar porosities observed for each wood, differences in maximum uptake are not justified by differences in volume associated to pores. Therefore, further wood characteristics may be involved in the maximum uptake capacity, which remain to be further investigated.

Focusing $K_{U}$ values, a higher variation was observed either among the chips of different size or water and wine contact. Water uptake was faster than wine uptake for all the chip sizes and oak varieties, as demonstrated by the lower time needed to attain half of $U_{\max }$, being also visible in the uptake profiles as wood in contact with water reached equilibrium earlier. Uptake is not only dependent on the sorbent material, but also on the sorbed matrix. Wood is a hygroscopic porous material, where liquid uptake occurs mainly through diffusion, following the established by Darcy's Law (Kang \& Chung, 2009). As described, wine viscosity is higher than water, due to its content in sugar, ethanol and glycerol (Nurgel \& Pickering, 2005; Pickering, Heatherbell, Vanhanen, \& Barnes, 1998). Therefore, taking into account Darcy's Law, as discussed by Morris Muskat (Muskat, 1937), the higher viscosity of wine when compared to water can be correlated with the slower uptake observed, hence reinforcing the validity of the models. $K_{U}$ values also demonstrate the importance of particle size on uptake kinetics. It can be clearly seen in the results that $K_{U}$ increased with increase of particle size, which is expected taking into account the described for liquid mass transfer into wood. Again, this observation can be explained by Darcy's Law, which postulates that flow varies in inverse proportion with the length of the section (Muskat, 1937). Therefore, the increase observed in the modeled $K_{U}$ values is again coherent with the postulated for liquid transport by diffusion. In further detail, for chips with a rectangular prism geometry, when plotting $K_{U}$ values versus particle surface area $(S A)$, a linear correlation between particle size and $K_{U}$ was hinted. For proper assessment of this hypothesis, further particle sizes were tested using French oak submerged in fortified wine, in order to check if the direct proportion and linear behavior would be maintained, being the results presented in Fig. 3. As seen by the $R^{2}$ of 0.9685 , a good correlation between particle size and $K_{U}$ was obtained, demonstrating the correlation between uptake time and particle size in isotherm conditions. Therefore, the empirical model proposed goes in good agreement with the reported for liquid transport in wood, being considered a good predictive tool for the process in matter.

As demonstrated, oak wood is a porous material and wine enters wood pores by diffusion during contact. Mass transfer of wine into wood was modeled and demonstrated as being of upmost importance in the enrichment observed, with uptake speed depending on particle size, and maximum uptake depending on wood type. At equilibrium, maximum retention capacity of wood was observed, with differences depending on wood type.

\subsection{Sorption of wine volatiles by oak wood}

After modeling uptake kinetics, characterization of wine volatiles in wood was performed at equilibrium, in order to assess its retention. Volatiles quantified in wood are presented in Table 3, which represent the compounds identified Control wood samples (N) showed typical wood extractives, such as volatile phenols, aldehydes, ketones and lactones, coherent with the reported for oak wood (De Rosso et al., 2009; Wilkinson et al., 2013). Toasted American oak presented higher levels of oak lactone and volatile phenols than toasted French oak which on its hand presented higher concentrations of furan compounds. The observed differences in oak composition are in good agreement with the previously reported for these wood varieties (Cadahía, Fernández de Simón, \& Jalocha, 2003; Chira \& Teissedre, 2014). Furan compounds, aldehydes and some volatile phenols were absent or found in lower concentrations in untoasted American oak when compared 
a)

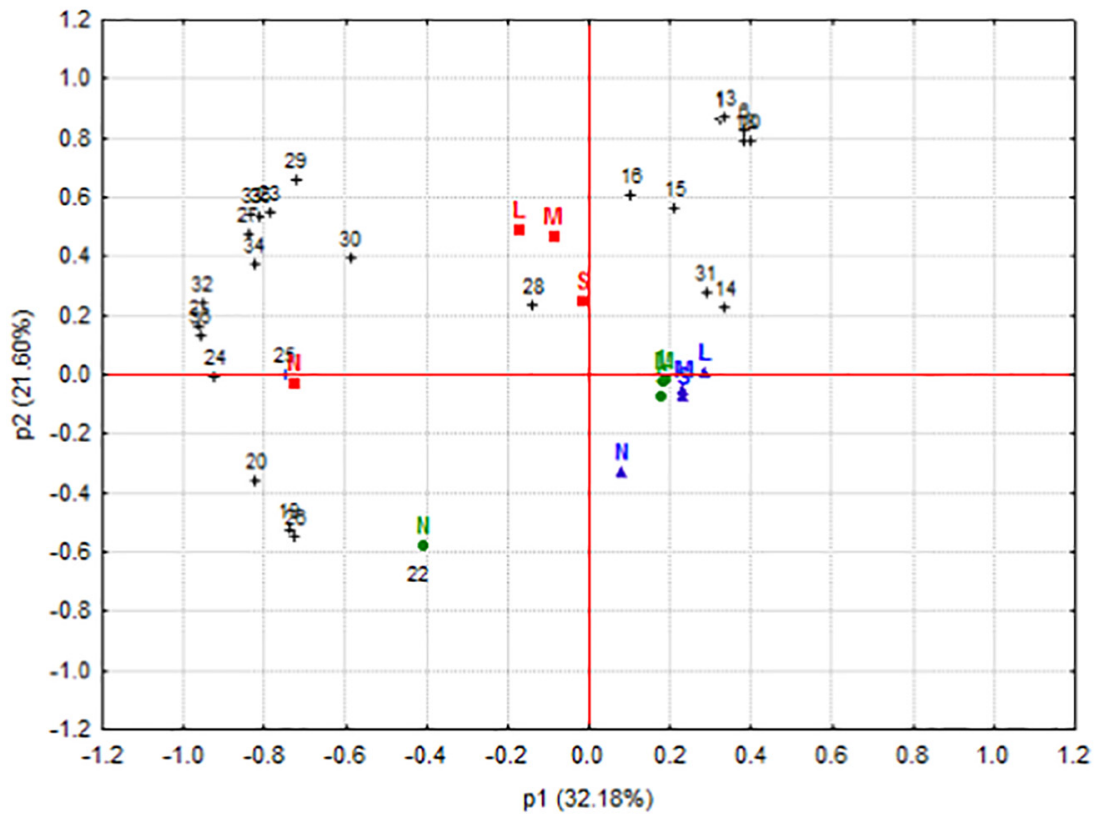

b)

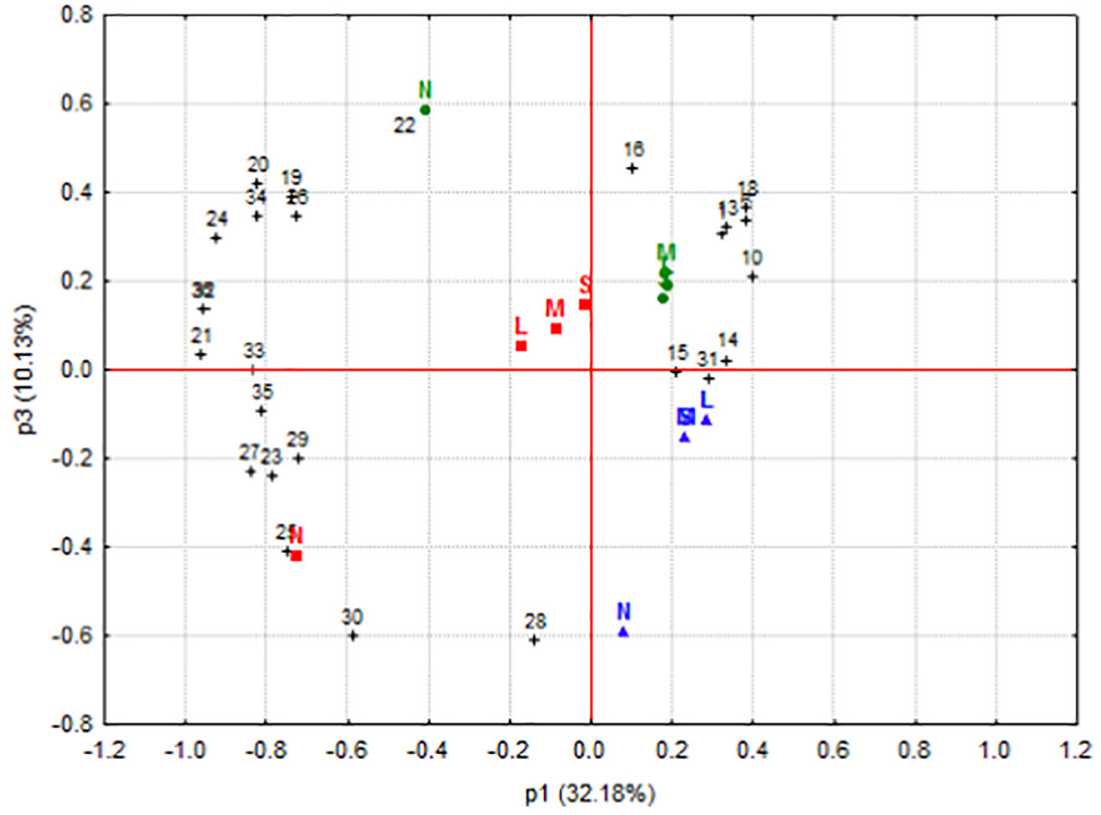

Fig. 4. Loadings scatterplot correlating toasted French oak (O ), toasted American oak $(\square)$ and untoasted American oak $(\mathbf{C})$ for unused oak controls (N) and after contact with fortified wine for small (S), medium (M) and large (L) oak chips, with the analyzed volatiles (represented by the numbers presented in Table 3) regarding a) the first and second component and b) the first and third component with the toasted variety. Concentration of these compounds in wood is strongly dependent on the burning step during cooperage (Caldeira, Mateus, \& Belchior, 2006; Canas, 2017; Fernández de Simón, Cadahía, del Álamo, \& Nevares, 2010), which justifies the lower concentrations found in untoasted American oak. After contact with wine, overall concentration of wood extractives was lower when compared to the control, as a result of extraction of wood volatiles, which are highly soluble in ethanol-water solutions (Mosedale \& Puech, 1998). No statistically significant differences were found in wood extractives concentration between the 3 particle sizes for toasted American and French oak and untoasted American oak. Therefore, extraction of wood volatiles occurred at the same level for the different particle sizes within each wood variety.

Regarding sorption, several wine volatiles were found in wood after contacting with wine, namely 3-methyl-1-butanol, 2-phenylethanol, ethyl lactate, monoethyl and diethyl succinate, diethyl malate, ethyl hexadecanoate, 4-ethylbenzaldehyde and octanoic acid. Most of these compounds were initially present in the wine matrix, as seen in Table 3, being that the ones appearing in wood correspond to those found in higher concentration in wine. Taking this and the previously discussed for wine uptake into account, absorption of wine can be the main contributor for the enrichment of wood with such compounds. On the other hand, Ramirez and his collaborators have previously demonstrated wood sorption of ethyl esters (ethyl hexanoate and ethyl octanoate), 2-phenylethanol and benzaldehyde from a synthetic hydroalcoholic matrix (Ramirez et al., 2001). Baiano and his collaborators have also demonstrated the disappearance of 2-phenylethanol, isoamyl acetate and 3-methyl-1-butanol along several other compounds in wines treated with oak chips, which implied that compounds were retained by wood (Baiano et al., 2016). 
In the present work, using a real wine matrix, ethyl esters, alcohols and aldehydes were also found in wood. Moreover, the concentration of volatiles retained in wood was not proportional to the concentrations observed in wine, indicating that selectivity took place, which has also been reported in Ramirez's work. Finally, 2-phenylethanol concentrations found in this work are within the same values reported for wood sorption of this compound (Ramirez et al., 2001), which confirms the previous findings and validates the results obtained. Therefore, the occurrence of wood sorption of wine volatiles, previously proposed by Ramirez, can be also involved in the wood enrichment described.

Focusing differences in volatile compounds retention, no statistically significant differences $(p>.05)$ were found in sorption of wine volatiles between the different particle sizes within each wood variety. Therefore, at equilibrium, retention of wine volatile compounds was independent of particle size or surface area to volume ratio. Such behavior is coherent with the discussed for wine uptake and again demonstrates, at compound level, that particle size did not affect maximum sorption capacity. Considering that no statistically significant differences were found between the chips of different size, the average concentration of retained wine volatiles was calculated for each wood, allowing an overall comparison between the different oak varieties. In this sense, American oak presented higher overall concentrations of 3methyl-1-butanol, diethyl succinate and octanoic acid than other woods. Ethyl hexadecanoate was not found in French oak, but found in both American oaks at similar concentrations. Monoethyl succinate was only found in the toasted oak varieties, being absent in untoasted American oak. No statistically significant differences were found between the different woods for the remaining volatiles deriving from wine sorption. Summing up, during contact with wine, besides being subjected to extraction, wood also becomes enriched with wine compounds, either by absorption or sorption. Volatile extraction and retention at equilibrium was independent of particle size, coherent with the observed for wine uptake. Some differences in volatiles retention were observed between the analyzed woods, suggesting that sorbent characteristics can be involved in sorption selectivity.

\subsection{Multivariate analysis of volatiles in wood}

For a better knowledge of the correlations between wood samples and their composition in volatiles, a Principal Component Analysis (PCA) was performed. Eleven components were extracted, which explained $96.47 \%$ of sum of squares, with the first three components explaining $63.90 \%$ of the overall correlations. With the obtained principal components, and the corresponding loadings regarding each variable, a cluster analysis was performed with the scatterplots presented in Fig. 4.

Most aspects previously discussed for volatile characterization were confirmed with the cluster analysis. As it can be seen, control wood samples were placed in opposite quadrants in the scatterplot, demonstrating the differences observed in volatile composition between each wood. On the other hand, woods contacted with wine were placed in similar clusters in the PCA, and different from the Control woods. Moreover, chips of different size appeared in most cases almost overlapped in the scatterplot, confirming the absence of statistically significant differences previously discussed between the different particles sizes within each wood. Toasted French oak and untoasted American oak showed similar loadings regarding the first and second component extracted, and minor differences regarding the third component. Overall, similar loadings regarding the third component were found between all woods after contact with wine and retained wine volatiles, namely 3-methyl-1-butanol, diethyl succinate, 2-phenylethanol, octanoic acid, ethyl lactate and ethyl hexadecanoate.

\section{Conclusions}

During ageing processes wine penetrates oak wood, entering its porous structure which is mainly driven by diffusion. Maximum sorption capacity depends principally on wood type and not on chip size. Nevertheless, particle size influences the time needed for attaining equilibrium. As a result of sorption, wine volatiles are retained in wood, which also depends on wood characteristics and is independent of particle size. Sorption and absorption phenomena are involved in the enrichment of wood with wine, the knowledge gained on these phenomena paves the way to make wood a controlled vector for transferring aroma compounds when applied for ageing different beverages.

\section{Declarations of interest}

None

\section{Acknowledgements}

This work was funded by the Portuguese Foundation for Science and Technology (FCT) under the scope of the strategic funding of UID/BIO/ 04469/2013 unit and COMPETE 2020 (POCI-01-0145-FEDER-006684) and BioTecNorte operation (NORTE-01-0145-FEDER-000004) funded by the European Regional Development Fund under the scope of Norte2020 - Programa Operacional Regional do Norte. FermentumEngenharia das Fermentações Lda. also participated in co-funding this work. Authors would like to thank Mr. Benoit Verdier and Seguin Moreau for supplying the woods and Mr. Paulo Coutinho and Quinta do Portal for supplying the fortified wine used in this work.

\section{References}

Baiano, A., De Gianni, A., Mentana, A., Quinto, M., Centonze, D., \& Del Nobile, M. A. (2016). Effects of the treatment with oak chips on color-related phenolics, volatile composition, and sensory profile of red wines: The case of Aglianico and Montepulciano. European Food Research and Technology, 242(5), 745-767. https:// doi.org/10.1007/s00217-015-2583-y.

Barrera-García, V. D., Gougeon, R. D., Di Majo, D., De Aguirre, C., Voilley, A., \& Chassagne, D. (2007). Different sorption behaviors for wine polyphenols in contact with oak wood. Journal of Agricultural and Food Chemistry, 55(17), 7021-7027. https://doi.org/10.1021/jf070598v.

Barrera-García, V. D., Gougeon, R. D., Karbowiak, T., Voilley, A., \& Chassagne, D. (2008). Role of wood macromolecules on selective sorption of phenolic compounds by wood. Journal of Agricultural and Food Chemistry, 56(18), 8498-8506. https://doi.org/10. 1021/jf801314n.

Barrera-García, V. D., Gougeon, R. D., Voilley, A., \& Chassagne, D. (2006). Sorption behavior of volatile phenols at the oak wood/wine interface in a model system. Journal of Agricultural and Food Chemistry, 54(11), 3982-3989. https://doi.org/10.1021/ jf053043d.

Bastard, A., Coelho, C., Briandet, R., Canette, A., Gougeon, R., Alexandre, H., ... Weidmann, S. (2016). Effect of biofilm formation by Oenococcus oeni on malolactic fermentation and the release of aromatic compounds in wine. Frontiers in Microbiology, 7(APR), 1-14. https://doi.org/10.3389/fmicb.2016.00613.

Cadahía, E., Fernández De Simón, B., \& Jalocha, J. (2003). Volatile compounds in Spanish, French, and American oak woods after natural seasoning and toasting. Journal of Agricultural and Food Chemistry, 51(20), 5923-5932. https://doi.org/10 1021/jf0302456.

Caldeira, I., Clímaco, M. C., Bruno De Sousa, R., \& Belchior, A. P. (2006). Volatile composition of oak and chestnut woods used in brandy ageing: Modification induced by heat treatment. Journal of Food Engineering, 76(2), 202-211. https://doi.org/10. 1016/j.jfoodeng.2005.05.008.

Caldeira, I., Mateus, A. M., \& Belchior, A. P. (2006). Flavour and odour profile modifications during the first five years of Lourinhã brandy maturation on different wooden barrels. Analytica Chimica Acta, 563, 264-273. https://doi.org/10.1016/j. aca.2005.12.008 1-2 SPEC. ISS.

Canas, S. (2017). Phenolic composition and related properties of aged wine spirits: Influence of barrel characteristics. A review. Beverages, 3(4), 55. https://doi.org/10. 3390/beverages3040055.

Canas, S., Caldeira, I., \& Belchior, A. P. (2013). Extraction/oxidation kinetics of low molecular weight compounds in wine brandy resulting from different ageing technologies. Food Chemistry, 138(4), 2460-2467. https://doi.org/10.1016/j.foodchem. 2012.12.018.

Chira, K., \& Teissedre, P. L. (2014). Chemical and sensory evaluation of wine matured in oak barrel: Effect of oak species involved and toasting process. European Food Research and Technology, 240(3), 533-547. https://doi.org/10.1007/s00217-0142352-3.

De Rosso, M., Cancian, D., Panighel, A., Dalla Vedova, A., \& Flamini, R. (2009). Chemical compounds released from five different woods used to make barrels for aging wines and spirits: Volatile compounds and polyphenols. Wood Science and Technology, 43(5-6), 375-385. https://doi.org/10.1007/s00226-008-0211-8. 
Ding, W.-D., Koubaa, A., Chaala, A., Belem, T., \& Krause, C. (2008). Relationship between wood porosity, wood density and methyl methacrylate impregnation rate. Wood Material Science and Engineering, 3(1-2), 62-70. https://doi.org/10.1080/ 17480270802607947.

Engelund, E. T., Thygesen, L. G., Svensson, S., \& Hill, C. A. S. (2013). A critical discussion of the physics of wood-water interactions. Wood Science and Technology, 47(1), 141-161. https://doi.org/10.1007/s00226-012-0514-7.

Fernández De Simón, B., Cadahía, E., del Álamo, M., \& Nevares, I. (2010). Effect of size, seasoning and toasting in the volatile compounds in toasted oak wood and in a red wine treated with them. Analytica Chimica Acta, 660(1-2), 211-220. https://doi.org/ 10.1016/j.aca.2009.09.031.

Garde-Cerdán, T., \& Ancín-Azpilicueta, C. (2006). Review of quality factors on wine ageing in oak barrels. Trends in Food Science and Technology, 17(8), 438-447. https:// doi.org/10.1016/j.tifs.2006.01.008.

Kang, W., \& Chung, W. Y. (2009). Liquid water diffusivity of wood from the capillary pressure-moisture relation. Journal of Wood Science, 55(2), 91-99. https://doi.org/ 10.1007/s10086-008-1009-x.

del Álamo, M., Nevares, I., Gallego, L., Martin, C., \& Merino, S. (2008). Aging markers from bottled red wine aged with chips, staves and barrels. Analytica Chimica Acta, 621(1), 86-99. https://doi.org/10.1016/j.aca.2008.05.014.

Le Floch, A., Jourdes, M., \& Teissedre, P. L. (2015). Polysaccharides and lignin from oak wood used in cooperage: Composition, interest, assays: A review. Carbohydrate Research, 417, 94-102. https://doi.org/10.1016/j.carres.2015.07.003.

Leofanti, G., Padovan, M., Tozzola, G., \& Venturelli, B. (1998). Surface area and pore texture of catalysts. Catalysis Today, 41(1-3), 207-219. https://doi.org/10.1016/ S0920-5861(98)00050-9.

MacKay, A. A., \& Gschwend, P. M. (2000). Sorption of monoaromatic hydrocarbons to wood. Environmental Science and Technology, 34(5), 839-845. https://doi.org/10. 1021/es9900858.

Mosedale, J. R. (1995). Effects of oak wood on the maturation of alcoholic beverages with particular reference to whisky. Forestry, 68(3), 203-230. https://doi.org/10.1093/ forestry/68.3.203.

Mosedale, J. R., \& Puech, J. L. (1998). Wood maturation of distilled beverages. Trends in Food Science and Technology, 9(3), 95-101. https://doi.org/10.1016/S0924-2244(98)
00024-7.

Muskat, M. (1937). The flow of fluids through porous media. Journal of Applied Physics, 8(4), 274-282. https://doi.org/10.1063/1.1710292.

Nurgel, C., \& Pickering, G. (2005). Contribution of glycerol, ethanol and sugar to the perception of viscosity and density elicited by model white wines. Journal of Texture Studies, 36(3), 303-323. https://doi.org/10.1111/j.1745-4603.2005.00018.x.

Ortega-Heras, M., González-Sanjosé, M. L., \& González-Huerta, C. (2007). Consideration of the influence of aging process, type of wine and oenological classic parameters on the levels of wood volatile compounds present in red wines. Food Chemistry, 103(4), 1434-1448. https://doi.org/10.1016/J.FOODCHEM.2006.10.060.

Pickering, G. J., Heatherbell, D. A., Vanhanen, L. P., \& Barnes, M. F. (1998). The effect of ethanol concentration on the temporal perception of viscosity and density in white wine. American Journal of Enology and Viticulture, 49(3), 306-318.

Plötze, M., \& Niemz, P. (2011). Porosity and pore size distribution of different wood types as determined by mercury intrusion porosimetry. European Journal of Wood and Wood Products, 69(4), 649-657. https://doi.org/10.1007/s00107-010-0504-0.

Ramirez, G. R., Lubbers, S., Charpentier, C., Feuillat, M., Voilley, A., \& Chassagne, D. (2001). Aroma compound sorption by oak wood in a model wine. Journal of Agricultural and Food Chemistry, 49(8), 3893-3897. https://doi.org/10.1021/ jf001334a.

Ribéreau-Gayon, P., Glories, Y., Maujean, A., \& Dubourdieu, D. (2006). Handbook of enology, the chemistry of wine: Stabilization and treatments: Second edition. Handbook of Enology, The Chemistry of Wine: Stabilization and Treatments: Second Edition. Vol. 2John Wiley \& Sons Inchttps://doi.org/10.1002/0470010398.

Russell, I. (2003). Whisky: Technology, production and marketing. Academic Press.

Spitaels, F., Wieme, A. D., Janssens, M., Aerts, M., Daniel, H. M., Van Landschoot, A., ... Vandamme, P. (2014). The microbial diversity of traditional spontaneously fermented lambic beer. PLoS One, 9(4), https://doi.org/10.1371/journal.pone.0095384.

Wilkinson, K., Li, S., Grbin, P., \& Warren, P. (2013). Barrel reclamation : Everything that's old can be new again. Australian and New Zealand Grapegrower and Winemaker, 594, $70-72$

Zillig, W., Janssen, H., Carmeliet, J., \& Derome, D. (2006). Liquid water transport in wood: Towards a mesoscopic approach. In Research in Building Physics and Building Engineering: Proceedings of "3rd International Building Physics Conference, 107-114. 